ORIGINAL ARTICLE

\title{
Incidence and lifetime costs of injuries in the United States
}

\author{
P Corso, E Finkelstein, T Miller, I Fiebelkorn, E Zaloshnja
}

Injury Prevention 2006;12:212-218. doi: 10.1136/ip.2005.010983

Background: Standardized methodologies for assessing economic burden of injury at the national or international level do not exist.

Objective: To measure national incidence, medical costs, and productivity losses of medically treated injuries using the most recent data available in the United States, as a case study for similarly developed countries undertaking economic burden analyses.

See end of article for Method: The authors combined several data sets to estimate the incidence of fatal and non-fatal injuries in 2000. They computed unit medical and productivity costs and multiplied these costs by corresponding incidence estimates to yield total lifetime costs of injuries occurring in 2000.

authors' affiliations

Correspondence to:

Dr P Corso, Centers for

Disease Control and

Prevention; National

Center for Injury

Prevention and Control; 4770 Buford Highway NE, Mailstop K60, Atlanta, GA 30341, USA; pcorso@cdc.gov

Accepted 29 March 2006
Main outcome measures: Incidence, medical costs, productivity losses, and total costs for injuries stratified by age group, sex, and mechanism.

Results: More than 50 million Americans experienced a medically treated injury in 2000, resulting in lifetime costs of $\$ 406$ billion; $\$ 80$ billion for medical treatment and $\$ 326$ billion for lost productivity. Males had a $20 \%$ higher rate of injury than females. Injuries resulting from falls or being struck by/against an object accounted for more than $44 \%$ of injuries. The rate of medically treated injuries declined by $15 \%$ from 1985 to 2000 in the US. For those aged 0-44, the incidence rate of injuries declined by more than $20 \%$; while persons aged 75 and older experienced a $20 \%$ increase.

Conclusions: These national burden estimates provide unequivocal evidence of the large health and financial burden of injuries. This study can serve as a template for other countries or be used in intercountry comparisons.
A ccording to the World Health Organization (WHO), injuries are a leading cause of the global burden of death and disability for all age groups below age $60{ }^{1}$ Injuries adversely affect the health and welfare of all people, regardless of country of origin or economic status, through premature death, disability, medical costs, and lost productivity. Estimating the magnitude of this burden is critical both for assessing the relative burden of injuries compared with other preventable health problems within a population, and for determining the appropriate level of national investment for specific injury prevention activities. The effort to monetize the national burden of injuries is an important first step in understanding the burden that injuries place on society, and for comparing national burden estimates between countries.

Few guidelines exist at a national ${ }^{2-4}$ or international level for conducting analyses to assess economic burden, although the WHO is leading a global effort in this area for violence (personal communication, Alexander Butchart, WHO, 2006). Thus, economic burden estimates are non-comparable across time within and between countries. Sources of non-comparability include methods used, annual versus lifetime cost approaches, and availability of epidemiologic and cost data.

The analyses reported herein update national injury burden estimates in the United States. They also serve as a case study for similarly developed countries undertaking economic burden analyses. We estimate the incidence, lifetime medical costs, and value of lost productivity (due to morbidity and mortality) across multiple strata (for example, age, sex, mechanism) for medically treated injuries that occurred in 2000. Because our incidence and medical cost estimates use methods similar to those employed in a previous economic burden report, ${ }^{5}$ we are able to examine how the relative burden of injuries has shifted in the US since 1985. Our methods can serve as a template for other countries undertaking a similar burden analysis and our estimates can be used in intercountry comparisons.

\section{DATA AND METHODS}

We define injuries using the following International Classification of Diseases (ICD) 9th Edition, Clinical Modification diagnosis codes: 800-909.2, 909.4, 909.9, 910994.9, 995.5-995.59, and 995.80-995.85.* Diagnoses 905-909 (late effects of injury) and 958 (certain early complications of trauma) are excluded, as is cumulative trauma. Using this definition, injury incidence counts and rates are presented for three mutually exclusive categories that reflect injury severity: (1) injuries resulting in death, including deaths occurring within and outside a healthcare setting; (2) injuries resulting in hospitalization with survival to discharge; and (3) injuries that receive medical attention without hospitalization. The latter category includes injuries resulting in an emergency department visit, an office based visit, or a hospital outpatient visit. We sum unduplicated injuries across treatment settings to quantify total injuries. Injuries that are not medically attended are excluded from this analysis.

We use a societal perspective to report the incidence and lifetime costs for injuries stratified by age group, sex, and mechanism. Table 1 lists the ICD codes used to define

* Includes: fractures; dislocations; sprains and strains; intracranial injury; internal injury of thorax, abdomen, and pelvis; open wound of the head, neck, trunk, upper limb, and lower limb; injury to blood vessels; late effects of injury, poisoning, toxic effects, and other external causes, excluding those from complications of surgical and medical care and drugs or from medicinal or biological substances; superficial injury; contusion; crushing injury; effects of foreign body entering through orifice; burns; injury to nerves and spinal cord; traumatic complications and unspecified injuries; poisoning and toxic effects of substances; other and unspecified effects of external causes; child maltreatment syndrome; adult maltreatment, unspecified; adult physical abuse; adult emotional or psychological abuse; adult sexual abuse; adult neglect (nutritional); other adult abuse and neglect.

Abbreviations: DCl, detailed claim information; HCUP-NIS, Healthcare Cost and Utilization Project-Nationwide Inpatient Sample; MEPS, Medical Expenditure Panel Survey; NVSS, National Vital Statistics System; WHO, World Health Organization. 
Table 1 Classification of injury codes by mechanism of injury

\begin{tabular}{|c|c|c|c|}
\hline Mechanism & ICD-9 codes & ICD- 10 codes & $\begin{array}{l}\text { NEISS cause of } \\
\text { injury codes }\end{array}$ \\
\hline $\mathrm{MV} /$ other road user & $\begin{array}{l}\text { E800.2-3; E801.2-3; E803.2-3; E804.2-3; } \\
\text { E805.2-3; E806.2-3; E807.2-3; E810-E819; } \\
\text { E820.6-7; E821.6-7; E822.6-7; E823.6-7; } \\
\text { E824.6-7; E825.6-7; E826.0,1,9; E827.0-1; } \\
\text { E828.0-1; E829.0-1; E958.5;E967.5; E988.5 }\end{array}$ & $\begin{array}{l}\text { V02.1,9; V03.1,9; V04.1,9; V09.2; V01; V05; V06; } \\
\text { V02.0; V03.0; V04.0; V09.0,1,3,9; V10; V1 1; } \\
\text { V15-V18; V12.3-9; V13.3-9; V14.3-9; V12.0-2; } \\
\text { V13.0-2; V14.0-2; V14.0-2; V19.0-3; V19.4-6; V19.8; } \\
\text { V19.9; V20.3-9 ... V28.3-9; V29.4-9; V30.4-9 ... } \\
\text { V79.4-9; V80.3-5; V8 }\end{array}$ & $01 ; 02 ; 03 ; 04$ \\
\hline Falls & E880-E888; E957; E968.1; E987 & W00-W19; X80; Y01; Y30 & 06 \\
\hline Struck by/against & E916-E917; E960.0; E968.2; E973; E975 & W20-W22; W50-W52; X79; Y00-Y04; Y35.3; Y29 & 07 \\
\hline Cut/pierce & E920; E956; E966; E974; E986 & W25-W29; W45; X78; X99; Y28; Y35.4 & 08 \\
\hline Fire/burn & $\begin{array}{l}\text { E890-E899; E924; E958.1; E958.2; E958.7; } \\
\text { E961; E968.0; E968.3; E988.1; E988.2; E988.7 }\end{array}$ & $\begin{array}{l}\mathrm{X} 00-\mathrm{X} 09 ; \mathrm{X} 76 ; \mathrm{X} 97 ; \mathrm{Y} 26 ; \mathrm{Y} 36.3 ; \mathrm{X} 10-\mathrm{X} 19 ; \mathrm{X} 77 \\
\mathrm{X} 98 ; \mathrm{Y} 27\end{array}$ & 10 \\
\hline Poisoning & $\begin{array}{l}\text { E850-E869; E950-E952; E962; E972; } \\
\text { E980-E982 }\end{array}$ & $X 40-X 49 ; X 60-X 69 ; X 85-X 90 ; Y 10-Y 19 ; Y 35.2$ & 11 \\
\hline Drowning/submersion & E830; E832; E910; E954; E964; E984 & W65-W74; X71; X92; Y21 & 13 \\
\hline Firearm/gunshot & $\begin{array}{l}\text { E922; E955.0-4; E955.6; E965.0-4; E965.6; } \\
\text { E970; E979.4; E985.0-4; E985.6 }\end{array}$ & W32-W34; X72-X74; X93-X95; Y22-Y24; Y35.0 & $18 ; 19$ \\
\hline Other & $\begin{array}{l}\text { E800.0,1,8,9 . E807.0,1,8,9; E820-E825; } \\
\text { E826.2,3,4,8,9 ... E828.2,3,4,8,9; E829.4,8,9; } \\
\text { E831-E845; E958.6; E988.6; E919 }\end{array}$ & $\begin{array}{l}\text { V20.0-2 ... V28.0-2; V29.0-3 ... V79.0-3; } \\
\text { V80.0,1,2,6,7,8,9; V81.0,2,3,4,5,6,7,8,9; } \\
\text { V82.0,2,3,4,5,6,7,8,9; V83.4-9 ..V86.4-9; V87.9; } \\
\text { V88.0-9; V89.0,1,3,9; X82; Y03; Y32; V90-V99; } \\
\text { Y36.1; W24; W30-W31; W75-W84; X91; X70; } \\
\text { Y20; W92-W99; X20-X39; X51-X57; W }\end{array}$ & $\begin{array}{l}05 ; 09 ; 12 ; 14 ; \\
16 ; 17 ; 20 ; 88 ; 99\end{array}$ \\
\hline
\end{tabular}

ICD-9, International Classification of Diseases, 9th Edition; ICD-10, International Classification of Diseases, 10th Edition; NEISS, National Electronic Injury Surveillance System.

mechanisms. Finkelstein et $a l^{6}$ fully describe the methods used to conduct this analysis, which we summarize here.

\section{Incidence}

All data were taken from a variety of national, state, and other published sources. Fatal injury counts were taken from the 2000 National Vital Statistics System (NVSS) data, which include a census of fatalities in the United States.

We estimated the incidence of non-fatal injuries that resulted in medical treatment without hospitalization or emergency department (ED) treatment from the 1999 Medical Expenditure Panel Survey (MEPS), which is a survey of the civilian, non-institutionalized population. Because the MEPS sample size for non-fatal hospitalized and ED treated injuries is small, we estimated the incidence of these injuries using other sources with much larger samples. We used the 2000 Healthcare Cost and Utilization Project-Nationwide Inpatient Sample (HCUP-NIS) for counts of hospitalized injuries. The HCUP-NIS provides discharge abstracts on 7.45 million inpatient stays. We counted records that indicated a live discharge and an injury diagnosis in any of the first three diagnosis fields.

We estimated the incidence of injuries treated in the ED from the 2001 National Electronic Injury Surveillance System - All Injury Program (NEISS-AIP). (Note: 2001 is the first complete year of NEISS data collection.)

MEPS, HCUP-NIS, and NEISS-AIP include weights which we applied to generate nationally representative estimates. These data let us include only medically treated injuries in this analysis. However, musculoskeletal injuries are the most frequently reported occupational injuries. ${ }^{7}$ To the extent that these musculoskeletal injuries and other injuries are not medically treated, we excluded them.

For the denominator of the incidence rates, we used population counts from the 1999 MEPS. Although we use a mix of data from 1999 through 2001, we assume the incidence of injuries did not differ over this period and report injuries as if for a single year, 2000.

\section{Costs}

We computed unit costs for medical and productivity loss injuries by the same strata identified for incidence, separately for fatal and non-fatal injuries, and multiplied these costs by corresponding incidence estimates to yield total costs. We converted all costs to year 2000 dollars using the relevant component of the Consumer Price Index (CPI). ${ }^{8}$ All future costs were converted to present value using a $3 \%$ discount rate.

\section{Medical costs}

For fatalities, we computed medical costs separately for five places of death identified in the 2000 NVSS data: death-onscene/at home, death-on-arrival to the hospital, death at the ED, death at the hospital after inpatient admission, and death at a nursing home. Depending on place of death, the medical costs incurred might include coroner/medical examiner (C/ME), medical transport, ED, inpatient hospital, or nursing home.

We used MEPS data to quantify medical costs for nonhospitalized injuries. For hospitalized injuries, because of the small sample size of admitted injuries in MEPS, we primarily relied on other data sources. We used HCUP-NIS data and cost-to-charge ratios from the Agency for Healthcare Research and Quality to compute inpatient facility costs. We then used Medstat's Marketscan data to quantify nonfacility costs incurred during an inpatient admission.

Most injuries that require a hospitalization will also require additional treatment after discharge. To develop estimates of short to medium term medical costs for injuries requiring an inpatient admission, we multiplied total inpatient costs derived from the HCUP-NIS/Marketscan data by the ratio of all costs during the first 18 months of injury, on average, to the total inpatient costs for that kind of injury. We derived these ratios from 1996 to 1999 MEPS data. The ratio of total costs to inpatient costs was roughly 1.35 and ranged between 1.02 and 2.13, depending on the type of injury.

We used an identical strategy to Rice $e t a l^{5}$ for estimating long term medical costs (18+ months). We used multipliers derived from longitudinal 1979-88 detailed claim information (DCI) data on 463174 workers' compensation claims. The DCI file was unique and nothing similar has subsequently become available. This method implicitly assumes that while treatment costs vary over time, the ratio of 18 month costs to total lifetime costs has remained constant between the time the DCI data were reported and 2000. Average multipliers were 1.30 and 1.14 to estimate total medical costs for admitted and non-admitted cases, respectively. 


\begin{tabular}{|c|c|c|c|c|c|c|c|}
\hline & \multicolumn{2}{|l|}{ Fatal } & \multicolumn{2}{|l|}{ Total } & \multicolumn{3}{|c|}{ Costs (in millions) } \\
\hline & Incidence & Rate & Incidence & Rate & $\begin{array}{l}\text { Medical costs } \\
\text { (\$) }\end{array}$ & $\begin{array}{l}\text { Productivity } \\
\text { losses (\$) }\end{array}$ & Total costs (\$) \\
\hline Total & 149,075 & 54 & $50,127,098$ & 18,135 & $\$ 80,248$ & $\$ 326,042$ & $\$ 406,289$ \\
\hline $0-4$ & 3532 & 18 & $3,426,571$ & 17,403 & $\$ 3729$ & $\$ 12,264$ & $\$ 15,992$ \\
\hline $5-14$ & 3741 & 9 & $7,945,792$ & 19,249 & $\$ 8170$ & $\$ 26,400$ & $\$ 34,569$ \\
\hline $15-24$ & 23,698 & 63 & $8,818,414$ & 23,604 & $\$ 12,895$ & $\$ 66,940$ & $\$ 79,835$ \\
\hline $25-44$ & 48,487 & 59 & $15,553,007$ & 18,818 & $\$ 22,704$ & $\$ 141,188$ & $\$ 163,892$ \\
\hline $45-64$ & 31,935 & 53 & $8,814,553$ & 14,750 & $\$ 14,278$ & $\$ 66,311$ & $\$ 80,589$ \\
\hline $65-74$ & 10,595 & 60 & $2,379,274$ & 13,488 & $\$ 5865$ & $\$ 7541$ & $\$ 13,406$ \\
\hline $75+$ & 27,087 & 179 & $3,189,486$ & 21,067 & $\$ 12,608$ & $\$ 5399$ & $\$ 18,007$ \\
\hline Male & 103,900 & 77 & $26,565,230$ & 19,736 & $\$ 44,445$ & $\$ 238,688$ & $\$ 283,133$ \\
\hline $0-4$ & 2059 & 20 & $2,079,034$ & 20,244 & $\$ 2438$ & $\$ 8733$ & $\$ 11,170$ \\
\hline $5-14$ & 2397 & 11 & $4,541,429$ & 21,688 & $\$ 4973$ & $\$ 18,810$ & $\$ 23,783$ \\
\hline $15-24$ & 18,609 & 98 & $5,129,575$ & 27,026 & $\$ 8346$ & $\$ 52,930$ & $\$ 61,276$ \\
\hline $25-44$ & 37,126 & 92 & $8,553,856$ & 21,215 & $\$ 14,033$ & $\$ 107,019$ & $\$ 121,052$ \\
\hline $45-64$ & 23,313 & 81 & $4,208,735$ & 14,558 & $\$ 7999$ & $\$ 45,612$ & $\$ 53,611$ \\
\hline $65-74$ & 6916 & 87 & $1,055,713$ & 13,215 & $\$ 2704$ & $\$ 3873$ & $\$ 6578$ \\
\hline $75+$ & 13,480 & 228 & 996,889 & 16,827 & $\$ 3,952$ & $\$ 1712$ & $\$ 5663$ \\
\hline Female & 45,175 & 32 & $23,561,868$ & 16,616 & $\$ 35,803$ & $\$ 87,353$ & $\$ 123,156$ \\
\hline $0-4$ & 1473 & 16 & $1,347,538$ & 14,311 & $\$ 1291$ & $\$ 3531$ & $\$ 4822$ \\
\hline $5-14$ & 1344 & 7 & $3,404,363$ & 16,737 & $\$ 3197$ & $\$ 7589$ & $\$ 10,786$ \\
\hline $15-24$ & 5089 & 28 & $3,688,839$ & 20,059 & $\$ 4549$ & $\$ 14,010$ & $\$ 18,559$ \\
\hline $25-44$ & 11,361 & 27 & $6,999,151$ & 16,535 & $\$ 8671$ & $\$ 34,169$ & $\$ 42,840$ \\
\hline $45-64$ & 8622 & 28 & $4,605,818$ & 14,930 & $\$ 6279$ & $\$ 20,699$ & $\$ 26,978$ \\
\hline $65-74$ & 3679 & 38 & $1,323,561$ & 13,711 & $\$ 3160$ & $\$ 3668$ & $\$ 6828$ \\
\hline $75+$ & 13,607 & 148 & $2,192,597$ & 23,783 & $\$ 8656$ & $\$ 3687$ & $\$ 12,343$ \\
\hline
\end{tabular}

\section{Productivity losses}

We quantify temporary or short term work loss for non-fatal injuries using the approach presented by Lawrence et al, where the probability of an injury that resulted in lost workdays was combined with the mean workdays lost (conditional on having missed at least one day) per injury estimated. Averaged across all injuries, estimated temporary work loss was 11.1 days per injury. We computed work loss durations for injuries separately for admitted and nonadmitted cases for each age category, sex, and mechanism.

To apply a monetary value to temporary work loss, we multiplied estimated work loss days by the average daily wage and fringe benefit costs stratified by age group and sex from the Current Population Survey. Following numerous other studies, ${ }^{9-11}$ we relied on survey data that showed household work is lost on $90 \%$ of days that wage work is lost to injury. Using this ratio and the value of household work, ${ }^{12}$ we also imputed a value for household work lost.

To compute productivity loss due to permanent or long term disability, we considered permanent total disability and permanent partial disability separately. For death and other permanent total disability, we multiplied the present value of age and sex specific lifetime earnings and household production $^{12}$ by the probability of permanent disability for each type of injury. For permanent partial disability, we multiplied the earnings estimate by the probability of permanent partial disability and an additional factor that identified the percentage of disability that resulted from that type of injury. We then summed the results to compute the net productivity loss associated with permanent disability, including total and partial disability. The probabilities of permanent and partial disability and the percent disabled (by body part and nature of injury) were computed from DCI data by Lawrence et al. ${ }^{9}$ Application of these estimates to our analysis assumes that these probabilities are the same for injuries that do and do not occur on-the-job and that they have not changed significantly over time. Averaged across all injuries, our estimated percentage of lifetime productivity potential lost due to injury was $0.26 \%$ per injury.

\section{RESULTS}

In 2000, Americans suffered more than 50 million medically treated injuries. This equates to about 20 injuries per 100 males and 17 injuries per 100 females. Nearly 150000 (or $0.3 \%$ ) injuries were fatal. The total lifetime cost of injuries occurring in 2000 was approximately $\$ 406$ billion; $\$ 80$ billion for medical treatment and $\$ 326$ billion for lost productivity. Table 2 displays incidence counts and rates (per 100000 persons) and total lifetime cost of injuries by age category and sex.

Table 2 shows that for males, $92 \%$ of injuries occur among those younger than age 65 and $76 \%$ occur among those younger than age 45 . The greatest rate of injuries-27 per 100 males-occurs among males ages 15-24. For females, the injury trend by age group is different. Although $85 \%$ of injuries occur among females younger than age 65, with $65 \%$ occurring among those younger than age 45 , the greatest rate of injuries occurs among females older than age 75 (24 injuries per 100 females).

Overall, the rate of injury is $20 \%$ higher among males than it is among females; however, the rate differs by age group. Males younger than age 24 are more than $30 \%$ more likely to suffer an injury than females of the same age group. In contrast, females older than age 75 are about $40 \%$ more likely to suffer an injury than their male counterparts.

The overall incidence rate of fatal injuries among males is 77 per 100000 males, which is more than 2.4 times greater than the rate of fatal injuries among females ( 32 per $100000)$. Males older than age 65 represent only $10 \%$ of the US male population, yet this age group sustains $20 \%$ of all fatal injuries. Similarly, males older than age 75 represent $4 \%$ of the US male population, but account for $13 \%$ of fatal injuries. For all age groups of females younger than age 75 , the rate of fatal injuries is below 40 per 100 000; for females older than age 75 , however, the rate of fatal injuries increases to 148 per 100000 .

In total, medical and productivity losses resulting from injuries in 2000 exceed $\$ 400$ billion, with $80 \%$ of the total resulting from lost productivity. People aged $25-44$ (30\% of 
Table 3 Incidence counts and rates (per 100 000) and total lifetime costs of injuries by mechanism and sex, 2000

\begin{tabular}{|c|c|c|c|c|c|c|c|}
\hline & \multicolumn{2}{|l|}{ Fatal } & \multicolumn{2}{|l|}{ Total } & \multicolumn{3}{|c|}{ Costs (in millions) } \\
\hline & Incidence & Rate & Incidence & Rate & $\begin{array}{l}\text { Medical } \\
\text { costs (\$) }\end{array}$ & $\begin{array}{l}\text { Productivity } \\
\text { losses (\$) }\end{array}$ & $\begin{array}{l}\text { Total costs } \\
\text { (\$) }\end{array}$ \\
\hline Total & 149,075 & 54 & $50,127,098$ & 18,135 & $\$ 80,248$ & $\$ 326,042$ & $\$ 406,289$ \\
\hline MV/Other road user & 43,802 & 16 & $5,010,439$ & 1813 & $\$ 14,026$ & $\$ 75,130$ & $\$ 89,156$ \\
\hline Falls & 14,052 & 5 & $11,566,742$ & 4185 & $\$ 26,892$ & $\$ 54,028$ & $\$ 80,920$ \\
\hline Struck by/Against & 1301 & 0 & $10,674,180$ & 3862 & $\$ 11,028$ & $\$ 37,104$ & $\$ 48,132$ \\
\hline Cut/Pierce & 2293 & 1 & $4,124,085$ & 1492 & $\$ 3662$ & $\$ 12,664$ & $\$ 16,326$ \\
\hline Fire/Burn & 3922 & 1 & 774,376 & 280 & $\$ 1345$ & $\$ 6202$ & $\$ 7546$ \\
\hline Poisoning & 20,261 & 7 & $1,267,465$ & 459 & $\$ 2236$ & $\$ 23,707$ & $\$ 25,944$ \\
\hline Drowning/Submersion & 4168 & 2 & 10,083 & 4 & $\$ 95$ & $\$ 5215$ & $\$ 5310$ \\
\hline Firearm/Gunshot & 28,722 & 10 & 131,013 & 47 & $\$ 1225$ & $\$ 35,226$ & $\$ 36,451$ \\
\hline Other/Unclassified* & 30,554 & 11 & $16,568,716$ & 5994 & $\$ 19,738$ & $\$ 76,767$ & $\$ 96,505$ \\
\hline Male & 103,900 & 77 & $26,565,232$ & 19,736 & $\$ 44,445$ & $\$ 238,688$ & $\$ 283,133$ \\
\hline MV/Other Road User & 29,686 & 22 & $2,551,330$ & 1895 & $\$ 8713$ & $\$ 55,214$ & $\$ 63,927$ \\
\hline Falls & 7647 & 6 & $5,201,676$ & 3865 & $\$ 11,778$ & $\$ 31,824$ & $\$ 43,602$ \\
\hline Struck by/Against & 1109 & 1 & $6,660,301$ & 4948 & $\$ 7493$ & $\$ 29,123$ & $\$ 36,617$ \\
\hline Cut/Pierce & 1678 & 1 & $2,602,084$ & 1933 & $\$ 2442$ & $\$ 9775$ & $\$ 12,217$ \\
\hline Fire/Burn & 2333 & 2 & 371,988 & 276 & $\$ 764$ & $\$ 4078$ & $\$ 4842$ \\
\hline Poisoning & 13,721 & 10 & 588,900 & 438 & $\$ 1063$ & $\$ 18,319$ & $\$ 19,382$ \\
\hline Drowning/Submersion & 3198 & 2 & 7016 & 5 & $\$ 61$ & $\$ 4389$ & $\$ 4450$ \\
\hline Firearm/Gunshot & 24,638 & 18 & 117,029 & 87 & $\$ 1081$ & $\$ 31,809$ & $\$ 32,890$ \\
\hline Other/Unclassified* & 19,890 & 15 & $8,464,908$ & 6289 & $\$ 11,050$ & $\$ 54,157$ & $\$ 65,207$ \\
\hline Female & 45,175 & 32 & $23,561,868$ & 16,616 & $\$ 35,803$ & $\$ 87,353$ & $\$ 123,156$ \\
\hline $\mathrm{MV} /$ Other road user & 14,116 & 10 & $2,459,105$ & 1734 & $\$ 5313$ & $\$ 19,916$ & $\$ 25,229$ \\
\hline Falls & 6405 & 5 & $6,365,066$ & 4489 & $\$ 15,114$ & $\$ 22,204$ & $\$ 37,318$ \\
\hline Struck by/Against & 192 & 0 & $4,013,880$ & 2831 & $\$ 3535$ & $\$ 7981$ & $\$ 11,516$ \\
\hline Cut/Pierce & 615 & 0 & $1,522,001$ & 1073 & $\$ 1221$ & $\$ 2889$ & $\$ 4109$ \\
\hline Fire/Burn & 1589 & 1 & 402,389 & 284 & $\$ 581$ & $\$ 2124$ & $\$ 2704$ \\
\hline Poisoning & 6540 & 5 & 678,565 & 479 & $\$ 1173$ & $\$ 5388$ & $\$ 6562$ \\
\hline Drowning/Submersion & 970 & 1 & 3067 & 2 & $\$ 34$ & $\$ 825$ & $\$ 859$ \\
\hline Firearm/Gunshot & 4084 & 3 & 13,984 & 10 & $\$ 144$ & $\$ 3417$ & $\$ 3561$ \\
\hline Other/Unclassified* & 10,664 & 8 & $8,103,807$ & 5715 & $\$ 8688$ & $\$ 22,610$ & $\$ 31,298$ \\
\hline \multicolumn{8}{|c|}{$\begin{array}{l}\text { *Injuries categorized as "other/unclassified" resulted from varied mechanisms: for fatal injuries, these other } \\
\text { mechanisms primarily resulted from inhalation/suffocation }(8 \%) \text { and unspecified }(8 \%) \text {; for hospitalized injuries, } \\
\text { these other mechanisms primarily resulted from unspecified mechanisms }(5 \%) \text {, overexertion }(2 \%) \text {, and other } \\
\text { transport }(2 \%) \text {; for less severe non-hospitalized injuries, these other mechanisms primarily resulted from } \\
\text { overexertion (11\%), bite/sting ( } 7 \% \text { ), and other transport ( } 2 \%) \text {. }\end{array}$} \\
\hline
\end{tabular}

the American population) account for $44 \%$ of injury attributable productivity losses; and those older than age 75 ( $5 \%$ of the American population) account for only $2 \%$ of injury attributable productivity losses.

The incidence of medically treated injuries captured in this analysis is almost evenly distributed between males and females. Males represent less than 50\% of the American population, yet they account for about $70 \%$ ( $\$ 283$ billion) of the total cost of injuries. This cost disparity between males and females primarily results from the higher rate of fatal injuries among males and the subsequent higher productivity losses. Additionally, because males, on average, receive higher wages than females, the value of lost productivity that results from a given injury is higher. In contrast, when focusing specifically on injury attributable medical spending, males account for $55 \%$ of the total.

Table 3 shows that overall, falls, struck by/against, and other/unclassified injuries accounted for more than $75 \%$ of injuries, and MV injuries accounted for an additional $10 \%$ of injuries. Although fire/burn, poisoning, drowning/submersion, and firearm/gunshot injuries are comparatively rare, these injuries are far more likely to be fatal than those caused by other mechanisms.

The rate of injuries among males is higher than that among females for every mechanism but falls: females are roughly $16 \%$ more likely than males to suffer a fall related injury. This is primarily driven by a high rate of fall related injuries among elderly females (results not shown). In contrast, males are roughly nine times more likely than females to suffer a firearm/gunshot injury and roughly twice as likely than females to suffer a drowning/submersion, cut/pierce, or struck by/against injury.

Combined, MV injuries ( $\$ 89$ billion) and fall injuries ( $\$ 81$ billion) account for more than $40 \%$ of the total costs of injuries. The distribution of total costs between medical treatment and lost productivity for these two mechanisms, however, differs considerably: $84 \%$ of the total costs of $\mathrm{MV}$ injuries result from lost productivity, whereas $67 \%$ of the total costs of fall injuries result from lost productivity.

\section{Comparison of 1985 and 2000 incidence rates}

The rate of medically treated injuries in the United States in 1985 was 21330 per 100000 persons. $^{5}$ We estimate that in 2000, this rate was 18135 per 100000 people, a reduction of about 15\% unadjusted for age. $\dagger$ Figure 1 compares the incidence rates, by age category, estimated for 1985 and 2000. For those aged $0-44$, the incidence rate of injuries declined by more than $20 \%$ from 1985 to 2000 . In contrast, the incidence rate of injuries among those older than age 45 increased, with people aged 75 and older experiencing a 20\% increase.

Figure 2 compares the rate of injuries per 100000 people in 1985 and 2000 for five categories of mechanisms, showing a decline in the rate of injuries since 1985 for all mechanisms. Firearm/gunshot and fire/burn injuries each decreased by

† In the original report, the estimate included injuries that resulted in lost workdays and/or bed days, but without medical treatment. Using data provided by authors of that report, we reduced their estimate to focus on injuries that received medical treatment, allowing us to fairly compare both estimates. 


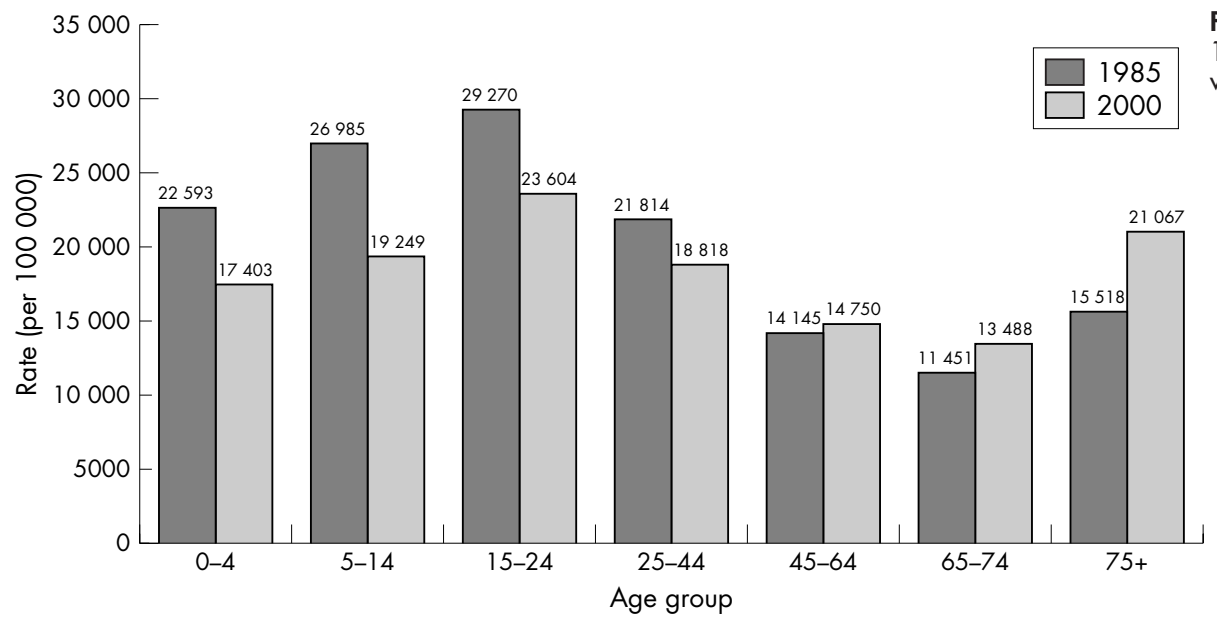

Figure 1 Incidence rate of injuries (per $100000)$ by age category, 1985 versus 2000.

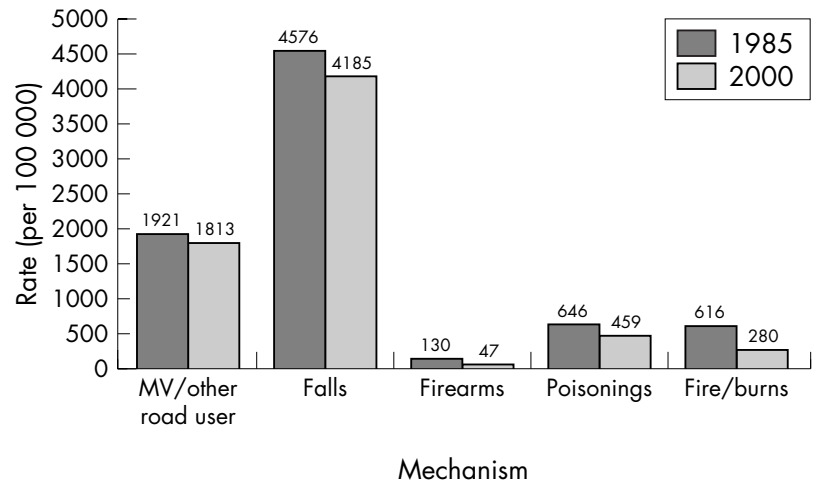

Figure 2 Incidence rate of injuries (per 100 000) by mechanism, 1985 versus 2000 .

more than 50\%. Poisoning, falls, and MV/other road user injuries decreased by $29 \%, 9 \%$, and $6 \%$, respectively.

Table 4 shows the incidence rate of injuries by age, sex, and selected mechanism for 1985 and 2000. For MV/other road user injuries among males, rates declined only marginally for all age groups except those aged 0-14 years of age. For males aged 5-14 years, the rate of MV/other road user injuries nearly doubled from 1985 (957 per 100 000) to 2000 (1733 per 100000$)$. For $\mathrm{MV} /$ other road user injuries among females, no consistent patterns of increase or decline emerged across age groups, although the greatest rate of decline occurred among females aged 75 years and older (from 1807 per 100000 in 1985 to 837 per 100000 in 2000).

For falls, the rate of injuries decreased for males in every age category; similarly, rates decreased for females up to age 45. But among older females (aged 75 years and older) the fall related injury rate more than doubled from 1985 (6576 per 100000 ) to 2000 ( 14104 per 100000 ). For firearms, the rate of injuries decreased from 1985 to 2000 for females in every age category and for males aged 15 years and older. For poisoning, the rate of injuries marginally declined from 1985 to 2000 for most gender/age categories, with the exception of females aged 15-24 years (where the rate increased fivefold) and females aged 65-74 years (where the rate increased twofold).

While the overall incidence of injuries declined 15\% from 1985 to 2000, the total medical costs of injuries (in real dollars) declined roughly $20 \%$. The decrease in cost, although driven in large part by the decrease in injury incidence, may also be the result of advances in trauma care, a shift toward managed care, and successful injury prevention efforts that minimize the harm resulting from injuries (for example, safety belts, helmets).

Table 4 The incidence rate of injuries (per 100 000) by age, sex, and mechanism, 1985 versus 2000

\begin{tabular}{|c|c|c|c|c|c|c|c|c|c|c|}
\hline & \multicolumn{2}{|c|}{$\mathrm{MV} /$ other road user } & \multicolumn{2}{|l|}{ Falls } & \multicolumn{2}{|c|}{ Firearm/gunshot } & \multicolumn{2}{|c|}{ Poisoning } & \multicolumn{2}{|c|}{ Fire/burn } \\
\hline & 1985 & 2000 & 1985 & 2000 & 1985 & 2000 & 1985 & 2000 & 1985 & 2000 \\
\hline Male & 1966 & 1895 & 4577 & 3865 & 137 & 87 & 671 & 438 & 601 & 276 \\
\hline $0-4$ & 627 & 720 & 7400 & 7388 & 2 & 5 & 1996 & 1089 & 819 & 661 \\
\hline $5-14$ & 957 & 1733 & 6612 & 5716 & 72 & 143 & 654 & 68 & 381 & 127 \\
\hline $15-24$ & 3780 & 3392 & 4321 & 3176 & 220 & 197 & 453 & 431 & 824 & 433 \\
\hline $25-44$ & 2418 & 2374 & 3159 & 2660 & 246 & 87 & 654 & 528 & 787 & 266 \\
\hline $45-64$ & 1590 & 1323 & 3347 & 2639 & 48 & 34 & 525 & 351 & 257 & 260 \\
\hline $65-74$ & 958 & 969 & 4872 & 3934 & 41 & 27 & 512 & 662 & 515 & 95 \\
\hline $75+$ & 994 & 903 & 8704 & 8331 & 54 & 39 & 322 & 236 & 443 & 91 \\
\hline Female & 1828 & 1734 & 4575 & 4489 & 116 & 10 & 595 & 479 & 647 & 284 \\
\hline $0-4$ & 743 & 440 & 7612 & 5885 & 2 & 2 & 1869 & 463 & 600 & 427 \\
\hline $5-14$ & 1116 & 1338 & 6645 & 4561 & $9 \overline{4}$ & 10 & 661 & 246 & 105 & 127 \\
\hline $15-24$ & 2966 & 3353 & 4794 & 2978 & 116 & 23 & 250 & 1309 & 612 & 228 \\
\hline $25-44$ & 2329 & 2168 & 3485 & 2988 & 256 & 11 & 558 & 356 & 1195 & 178 \\
\hline $45-64$ & 1221 & 1362 & 2894 & 4137 & 10 & 7 & 431 & 192 & 394 & 512 \\
\hline $65-74$ & 1234 & 1181 & 3206 & 5120 & 5 & 4 & 597 & 1244 & 259 & 316 \\
\hline $75+$ & 1807 & 837 & 6576 & 14,104 & 6 & 3 & 177 & 155 & 441 & 332 \\
\hline
\end{tabular}




\section{DISCUSSION}

The methodology for estimating national economic burden of injury presented in this analysis may be applied to other countries, recognizing the following caveats in our approach and in our data. First, a single data source for calculating these estimates does not exist. Consequently, we were forced to use myriad data sources, each with limitations. Some sources were old, others were based on non-nationally representative samples, and all were subject to reporting and measurement error. These limitations not only increase the lack of precision around the estimates, but may result in additional bias.

Second, injuries treated by mental health professionals, chiropractors, acupuncturists, and alternative medicine providers may not be included in the data or, if included, may not be coded with an injury diagnosis. As a result, our estimates would exclude these cases, along with other types of injuries (for example, musculoskeletal injuries reported by workers ${ }^{7}$ ) that, although potentially severe, did not receive medical treatment or had other non-injury related sequelae (for example, chronic diseases, depression and anxiety disorders, sexually transmitted diseases, and increased health risk behaviors such as smoking or alcohol and substance abuse). The net effect of excluding these cases may be substantial. For example, a survey of mental health providers $^{13}$ estimated that 3.4 million physical and sexual assaults resulted in mental health treatment, often without treatment in other medical settings. These treatment episodes are unlikely to be coded as injury related.

Productivity loss estimates, which rely upon a "human capital" approach, undervalue injuries to children, women, and the elderly because these groups either have no salary or earn lower wages. This effect may be even more pronounced in countries which are less economically developed than the US. The human capital approach also places lower values on the work of full time homemakers than on the work of people participating in the labor market, which might further depress the value placed on women's productivity losses relative to men's productivity losses.

The costs included in this analysis focus exclusively on medical and productivity costs for medically treated injuries only, and exclude other resource costs (for example, police services, caregiver time), costs for pain and suffering,${ }^{14}$ or other non-monetary costs that result from these or other non-medically treated injuries (such as reductions in functional capacity and quality of life). Despite the difficulty quantifying non-monetary outcomes (such as pain and suffering), excluding these outcomes would cause our total cost estimates to be substantially underestimated.

An additional limitation of both this paper and previous national estimates of injury burden ${ }^{5}$ is the lack of standard errors. The estimates generated from both analyses rely on multiple data sources and algorithms which make estimating standard errors difficult. For a sensitivity analysis of the trends comparison, we computed standard errors around the estimates in figure 1 based on relative standard errors of age specific injury prevalence generated entirely from the MEPS data (results available upon request). Because the MEPS sample of roughly 25000 individuals is smaller than many of the datasets used in the analyses and because MEPS captures all injuries that require medical attention, it provides a conservative estimate of the confidence of the age specific estimates. Using these relative standard errors, the estimates from the 1989 report are outside of the year 2000 confidence intervals for all age categories except ages 45-64. If MEPS relative standard errors are applied to both sets of prevalence estimates, the estimates remain statistically different for all age categories except ages $45-64$ and ages 65-74.

\section{Key points}

- Injury burden in the United States exceeded $\$ 400$ billion in medical care costs and productivity losses in 2000.

- $18 \%$ of Americans were medically treated for injury.

- Among age groups, treated injury rates ranged from $13.5 \%$ to $23.6 \%$.

- Between 1985 and 2000, injury rates declined dramatically in the US among people under age 45 but rose substantially among the elderly.

- Falls and the interrelated category of being struck by or against objects accounted for more than $30 \%$ of injury costs, making them a strong prevention target.

Even with confidence intervals included, comparisons between these results and the 1985 estimates $^{5}$ require additional caveats. Different data sources were used for some of the analyses. Most current data sources capture better cost data and injury information than previously available, but some of the same sources collect different or less information than before. Finally, the cause for the change in incidence from 1985 to 2000 is unknown. The change may be due to real population based decreases in the incidence of injury, or the change may reflect changes in health seeking behavior, delivery, or access to care. With differing national healthcare delivery systems, intercountry comparison of injury burden across time is even more challenging.

Despite these limitations, the estimates reported above should be viewed as the best available estimates of injury incidence and costs in the US to date, and can serve as a template for other countries undertaking the same analyses or as a source for intercountry comparison of burden estimates. Future studies with better data will improve upon the methodology and results. These data provide unequivocal evidence that injuries create a large health and financial burden. Policy makers have the ability to influence this burden through mechanisms such as money, support, research, advocacy, legislation, and implementation of successful injury prevention programs. All strategies should be considered in efforts to reduce the burden that injuries impose on society.

\section{Authors' affiliations \\ P Corso, Centers for Disease Control and Prevention, Atlanta, GA, USA \\ E Finkelstein, Research Triangle Park, NC, USA \\ I Fiebelkorn, RTI International \\ T Miller, E Zaloshnja, Pacific Institute for Research and Evaluation, Calverton, MD, USA}

The findings and conclusions in this study are those of the authors and do not necessarily represent the views of the Centers for Disease Control and Prevention.

\section{REFERENCES}

1 Peden M, McGee K, Krug E, eds. Injury: A leading cause of the burden of disease, 2000. Geneva: The World Health Organization, 2002.

2 EMC (Erasmus Medical Center) and CSI (Consumer Safety Institute). A surveillance based assessment of medical costs of injury in Europe: Phase 2. Final Report. Rotterdam and Amsterdam: EMC and CSI, 2004.

3 Bowman B. Towards a South African injury costing model. A review of the literature for the development of a process path. African Safety Promotion 2002; 1:55-64

4 TRL (Transport Research Laboratory). Costing road accidents in developing countries. Overseas Road Note 10. Crowthorne: TRL, 1995.

5 Rice D, MacKenzie E, and Associates. Cost of injury in the United States: A report to Congress. San Francisco, CA: Institute for Health \& Aging, 
University of California and Injury Prevention Center, The Johns Hopkins University, 1989

6 Finkelstein E, Corso P, Miller T. Incidence and economic burden of injuries in the United States, 2000. New York, NY: Oxford University Press, 2006.

7 NIOSH. Worker health chartbook 2004. Cincinnati, OH: US Department of Health and Human Services, Public Health Service, Centers for Disease Control and Prevention, National Institute to Occupational Safety and Health, DHHS (NIOSH) Publication No 2004-146, 2004

8 US Census Bureau. Table 713. Consumer Price Indexes (COI-U) by Major Groups: 1980 to 2002. Statistical abstract of the United States: 2003. Washington, DC: US Census Bureau, 2003:475.

9 Lawrence B, Miller T, Jensen A, et al. Estimating the costs of non-fatal consumer product injuries in the United States. Inj Control Saf Promot 2000;7:97-113.
10 Miller T, Romano E, Spicer R. The cost of childhood unintentional injuries and the value of prevention. Future Child 2000;10:137-63.

11 Zaloshnja E, Miller T, Romano E, et al. Crash costs by body part injured, fracture involvement, and threat to life severity, United States, 2000. Accid Anal Prev 2004:36:415-27.

12 Haddix A, Teutsch S, Corso P. Prevention effectiveness: A guide to decision analysis and economic evaluation. New York, NY: Oxford University Press, 2003.

13 Cohen M, Miller T. The cost of mental health care for victims of crime. $J$ Interpers Violence 1998;13:93-110.

14 Leigh J, Waehrer G, Miller T, et al. Costs of occupational injury and illnesses across industries. Scand J Work Environ Health 2004;30:199-205.

\section{Clinical Evidence-Call for contributors}

Clinical Evidence is a regularly updated evidence-based journal available worldwide both as a paper version and on the internet. Clinical Evidence needs to recruit a number of new contributors. Contributors are healthcare professionals or epidemiologists with experience in evidence-based medicine and the ability to write in a concise and structured way.

Areas for which we are currently seeking contributors:

- Pregnancy and childbirth

- Endocrine disorders

- Palliative care

- Tropical diseases

We are also looking for contributors for existing topics. For full details on what these topics are please visit www.clinicalevidence.com/ceweb/contribute/index.jsp

However, we are always looking for others, so do not let this list discourage you.

Being a contributor involves:

- Selecting from a validated, screened search (performed by in-house Information Specialists) epidemiologically sound studies for inclusion.

- Documenting your decisions about which studies to include on an inclusion and exclusion form, which we keep on file.

- Writing the text to a highly structured template (about 1500-3000 words), using evidence from the final studies chosen, within 8-10 weeks of receiving the literature search.

- Working with Clinical Evidence editors to ensure that the final text meets epidemiological and style standards.

- Updating the text every 12 months using any new, sound evidence that becomes available. The Clinical Evidence in-house team will conduct the searches for contributors; your task is simply to filter out high quality studies and incorporate them in the existing text.

If you would like to become a contributor for Clinical Evidence or require more information about what this involves please send your contact details and a copy of your CV, clearly stating the clinical area you are interested in, to CECommissioning@bmigroup.com.

\section{Call for peer reviewers}

Clinical Evidence also needs to recruit a number of new peer reviewers specifically with an interest in the clinical areas stated above, and also others related to general practice. Peer reviewers are healthcare professionals or epidemiologists with experience in evidence-based medicine. As a peer reviewer you would be asked for your views on the clinical relevance, validity, and accessibility of specific topics within the journal, and their usefulness to the intended audience (international generalists and healthcare professionals, possibly with limited statistical knowledge). Topics are usually 1500-3000 words in length and we would ask you to review between 2-5 topics per year. The peer review process takes place throughout the year, and out turnaround time for each review is ideally 10-14 days. If you are interested in becoming a peer reviewer for Clinical Evidence, please complete the peer review questionnaire at www. clinicalevidence.com/ceweb/contribute/peerreviewer.jsp 